\title{
O cuidado de enfermagem à pessoa que se submete à cirurgia para redução de peso*
}

\author{
Nursing care to weight reduction surgery patients
}

\author{
Cuidado de enfermería a la persona que se somete a cirugía de reducción de peso
}

Eliziani Gonçalves da Silva ${ }^{1}$, Zilanda Sorai de Oliveira², Sonia Ayako Tao Maruyama ${ }^{3}$, Aldenan Lima Ribeiro Corrêa da Costa ${ }^{4}$

\footnotetext{
* Este estudo é um recorte do projeto intitulado "Significados e Sentidos do Cuidado em condição crônica: um olhar sob a perspectiva socioantropológica", que foi desenvolvido pelo Grupo de Pesquisa Enfermagem Saúde e Cidadania da Faculdade de Enfermagem da Universidade Federal de Mato Grosso.

1 Enfermeira. Discente do Programa de Pós-Graduação em Enfermagem, nível Mestrado, da Faculdade de Enfermagem da Universidade Federal de Mato Grosso (FAEN/UFMT). Cuiabá, MT, Brasil. E-mail: elizianisilva@hotmail.com.

${ }^{2}$ Enfermeira. Cuiabá, MT, Brasil. E-mail: zilanda sorai@hotmail.com.

${ }^{3}$ Enfermeira, Doutora em Enfermagem Fundamental. Professora Adjunta da FAEN/UFMT. Cuiabá, MT, Brasil. E-mail: soniamaruyama@gmail.com.

${ }^{4}$ Enfermeiro, Doutor em Enfermagem Fundamental. Professor Adjunto da FAEN/UFMT. Cuiabá, MT, Brasil. E-mail: aldenanlima@gmail.com.
}

\section{RESUMO}

Questiona-se a percepção dos profissionais de enfermagem sobre as pessoas que fazem cirurgia para redução de peso, objetivando compreender o cuidado da enfermagem às pessoas que se submetem a esta cirurgia. Pesquisa compreensiva realizada por meio de entrevistas semiestruturadas e observação participante junto aos profissionais de enfermagem, no período de fevereiro a maio de 2011. A análise utilizada foi a temática e as categorias encontradas foram: o cuidado ao corpo físico, que relaciona o conhecimento técnico-científico às condições adequadas de trabalho e de recurso humanos, asseguradas legalmente, mas não garantidas institucionalmente; e o cuidado ao corpo social, que diz respeito às tecnologias relacionais, com ênfase na observação, na escuta, na fala, no diálogo e no vínculo. Os resultados evidenciam que a perspectiva sociocultural valoriza os comportamentos, as crenças e os significados como elementos importantes para a qualificação do cuidado.

Descritores: Enfermagem; Cuidados de Enfermagem; Cirurgia Bariátrica; Obesidade.

\section{ABSTRACT}

This study investigated the perception that nursing professionals make of weight reduction surgery patients, aiming to understand the nursing care that is provided to people who undergo this particular surgery. This comprehensive study was performed by means of semi-structured interviews and participant observation of nursing professionals, in the period from February to May of 2011. Thematic analysis was used and the identified categories were: physical body care, which relates technical-scientific knowledge with adequate working and staffing conditions, legally ensured, but not institutionally guaranteed; and social body care, which refers to relational technologies, with emphasis on observation, listening, talking, dialogue and bonding. Results show that the sociocultural perspective values behaviors, beliefs, and meanings as important elements to improve the quality of care.

Descriptors: Nursing; Nursing Care; Bariatric Surgery; Obesity.

\section{RESUMEN}

Se apunta a averiguar la percepción de los profesionales de enfermería acerca de las personas que se efectúan cirugía de reducción de peso, objetivando comprender el cuidado de enfermería para dichas personas. Investigación comprensiva, realizada mediante entrevistas semiestructuradas y observación participante, con los profesionales de enfermería, de febrero a mayo de 2011. Se utilizó análisis temático, las categorías encontradas fueron: el cuidado del cuerpo físico, que relaciona el conocimiento técnico-científico con las adecuadas condiciones laborales y de recursos humanos, aseguradas legalmente pero no garantizadas institucionalmente; y el cuidado al cuerpo social, que se expresa respecto a las tecnologías relacionales, con énfasis en la observación, la escucha, el discurso, el diálogo y el vínculo. Los resultados evidenciaron que la perspectiva sociocultural valoriza los comportamientos, las creencias y los significados como elementos importantes para la calificación del cuidado.

Descriptores: Enfermería; Atención de Enfermería; Cirugía Bariátrica; Obesidad. 


\section{INTRODUÇÃO}

A obesidade tem sido discutida e veiculada no cotidiano de saúde na perspectiva biomédica. No entanto, ela é compreendida "como um agravo de caráter multifatorial envolvendo desde questões biológicas às históricas, ecológicas, econômicas, sociais, culturais e políticas"(1), motivo pelo qual se constitui um desafio às práticas dos profissionais de saúde.

No mundo, a obesidade é reflexo das alterações que ocorreram na dinâmica da vida das pessoas, integrando questões de ordem econômica, social e, principalmente, cultural. Devido a estes fatores, é necessário um olhar abrangente reconhecendo os múltiplos aspectos relacionados à obesidade.

O tratamento para a obesidade considera inicialmente a mudança de comportamento, com modificações nos hábitos de vida, sendo a alimentação saudável e o aumento da atividade física as recomendações mais enfatizadas. Já a terapia medicamentosa tem sido indicada рага pessoas obesas que apresentam comorbidades, cujas modificações dietéticas e a adoção de atividade física por cinco anos não surtiram efeito. Entre os tratamentos farmacológicos, dietéticos, cognitivo-comportamentais, tratamentos heterodoxos e de suplementação nutricional, o cirúrgico tem sido uma das alternativas e vem se tornando uma prática crescente nas instituições de saúde(2).

Рara compreendermos o cuidado, na perspectiva dos profissionais de enfermagem, às pessoas que se submetem à cirurgia de redução de peso, defendemos que este cuidado tem uma dimensão não só técnica, mas também social e cultural. O cuidado à saúde pode ser ofertado no sistema formal de saúde, são os cuidados profissionais, e sua ênfase é sobre os aspectos biológicos e funcionais, mas também pode advir de ações terapêuticas realizadas por famílias e pessoas fora do âmbito profissional, considerados cuidados informais.

O cuidado pode ser desenvolvido por profissionais de saúde em suas diversas áreas, porém a profissão que tem "o cuidado como objeto epistemológico e como core de seu agir profissional é a enfermagem"(3). Esse cuidar busca "promover a vida, o potencial vital, o bem-estar dos seres humanos na sua individualidade, complexidade $e$ integralidade"(3), sendo este modo de pensar o cuidado a orientação deste estudo. Assim, embora a enfermagem seja orientada pelo modelo médico que tende a focalizar sobre esse modelo, reconhece que o seu cuidar envolve os cuidados técnicos, aspectos sociais e culturais presentes no contexto de vida, os quais compartilhamos nos grupos sociais.

Nas práticas dos profissionais da saúde, ao ampliar a perspectiva do cuidado às dimensões biológica, cultural e social do ser cuidado, é considerada a integralidade do ser humano ${ }^{(4-6)}$.Neste sentido, no cuidado busca-se o desenvolvimento de "atitudes e espaços de genuíno encontro intersubjetivo, de exercício de sabedoria prática para saúde, apoiado em tecnologias", entendendo-se a sabedoria prática como um saber "se conduzir frente às questões da práxis vital que não seguem leis universais ou modos de fazer conhecidos a priori, mas se desenvolvem como phrónesis, isto é, como um tipo de racionalidade que nasce da práxis e a ela se dirige de forma imediata na busca da construção compartilhada da Boa Vida"(7).

O cuidado busca, no encontro, construir o outro, mas também se construir. Daí a importância de serem apreendidos os valores, as posturas e as práticas dos profissionais, pois eles revelam a dimensão processual que o cuidado implica e, ao evidenciarmos estes aspectos, possibilitarão a compreensão do quanto as ações em saúde estão se orientando para a integralidade.

A busca pela compreensão dos aspectos sociais e culturais inseridos nos comportamentos das pessoas está pautada no fato de que "a construção de sentidos $e$ significados é parte de um movimento intrínseco às práticas de saúde. As relações possiveis entre os significantes ou elementos de significados expressos nas ações são construídas de acordo com os sentidos a eles atribuídos pelos atores/praticantes nas práticas"(8).

Os conceitos socioantropológicos possibilitam o discernimento dos modos como as pessoas se comportam e pensam nos contextos de vida e saúde. Apreender as falas e os comportamentos dos profissionais de enfermagem facilita desvendar os significados presentes, de maneira a compreender como o contexto social em que estão inseridos se relaciona aos modos de pensar e agir sobre as questões de saúde ${ }^{(9-10)}$.

Nesse panorama, nossos questionamentos são: como o profissional de enfermagem interpreta o cuidado às pessoas que fazem a cirurgia para redução de peso? Como cuidam e se relacionam com elas? 
Em busca de estudos sobre a temática da enfermagem às pessoas em obesidade, encontramos que os autores retratam as atualizações dos cuidados de enfermagem perioperatória, utilizando as diretrizes baseadas em evidências e as teorias de enfermagem, e recomendando que os profissionais de enfermagem observem suas crenças e atitudes frente à obesidade ${ }^{(11-}$ 14). Diante das repercussões que a cirurgia bariátrica ocasiona e que pode gerar sofrimento à pessoa a ela submetida, já que esta cirurgia não se limita apenas à perda de peso, é preciso que a atenção articule e integre os diferentes profissionais de saúde com vistas ao cuidado integral(15).

Com base nestas considerações, o objetivo deste estudo foi compreender o cuidado dos profissionais de enfermagem às pessoas que se submetem à cirurgia para redução de peso.

\section{METODOLOGIA}

A abordagem escolhida para este estudo foi a compreensiva, que visa a alcançar os fenômenos subjetivos e se aplica ao estudo das crenças, das opiniões, das interpretações, possibilitando acessar os significados presentes nas falas e comportamentos das pessoas, portanto, coerente com o objetivo deste estudo ${ }^{(16)}$.

O contexto escolhido foi a clínica cirúrgica de um Hospital Universitário no município de Cuiabá-MT, caracterizada por ter profissionais de enfermagem que cuidam, nas fases pré e pós-operatórias, da cirurgia para redução de peso no âmbito do SUS. A clínica possui 24 leitos, sendo um leito destinado às pessoas que se submetem à cirurgia para redução de peso.

Os critérios para seleção dos sujeitos foram: ter disponibilidade em participar do estudo e ter exercido o cuidado às pessoas que se submetem à cirurgia para redução de peso. Neste contexto, elegemos três profissionais: um auxiliar de enfermagem e dois técnicos de enfermagem. O critério de suficiência dos sujeitos foi a repetição de temas nas entrevistas.

O período de coleta ocorreu entre fevereiro e maio de 2011, feita por entrevistas gravadas e registros em diário de campo. Promovemos um primeiro encontro para avaliar a efetividade das técnicas, dos instrumentos de coleta e a viabilidade das questões norteadoras: como é para você cuidar de pessoas que se submetem à cirurgia para redução de peso? Como é sua experiência de cuidado? Fale como você cuida delas?

A análise dos dados ocorreu por meio da análise temática(16), tendo sido seguidas três etapas: após a transcrição das fitas, foi realizada a pré-análise, e a constituição do corpus de análise; na segunda etapa, realizamos os recortes das entrevistas e o ordenamento dos temas encontrados. Em seguida, procedeu-se ao agrupamento dos temas por afinidades, visando a alcançar o núcleo de compreensão do texto. Trabalhamos com os núcleos de sentido: significado da vida do obeso, sua história e bibliografia; concepção de vida do cuidado além do corpo físico, o corpo ideal, o sentido do cuidado e cidadania; e a concepção de corpo obeso forma, peso, recursos físicos, rotina, ritual e recursos humanos. Nesta etapa, houve a fragmentação e o reordenamento dos temas, chegando-se às seguintes categorias: o cuidado ao corpo físico e o cuidado ao corpo social.

Na etapa seguinte, foram feitas a interpretação dos resultados e a discussão segundo os referenciais socioculturais. Os dados foram discutidos à luz de autores pertinentes nas áreas da socioantropologia e da enfermagem.

As categorias estabelecidas neste estudo não buscaram por objetivo a fragmentação, mas a compreensão de que o cuidado de enfermagem tem se efetivado, não somente associado à concepção do corpo físico, mas inclusive que este cuidado se vincula a aspectos socioculturais dos profissionais e usuários.

Todos os procedimentos éticos foram considerados e, neste sentido, o anonimato dos sujeitos foi preservado, sendo eles identificados como Sujeito 1, Sujeito 2 e Sujeito 3. O projeto teve sua aprovação pelo Comitê de Ética em Pesquisa (CEP) do Hospital Universitário Júlio Müller (HUJM), sob o Protocolo n 792/CEP-HUJM/10 em 20/04/2010.

\section{RESULTADOS E DISCUSSÃO}

As narrativas dos profissionais de enfermagem descrevem as formas como eles entendem o cuidado à pessoa obesa no contexto da cirurgia para redução de peso. Foi possível apreender que estas narrativas incorporam significados relacionados aos valores, crenças e comportamentos compartilhados nos grupos sociais vivenciados ao longo de suas vidas. 
São envolvidos não só significados da sociedade, mas também aqueles que fazem parte da cultura da biomedicina, compartilhados no decorrer de sua formação profissional como de seu trabalho profissional. Apesar de compartilhar valores e crenças comuns, cada profissional de enfermagem entende o cuidado a estas pessoas de modo particular. Ao lado de suas particularidades, foi possível apreender que os significados evidenciados nas narrativas sobre o cuidado de enfermagem têm por referência os valores do corpo, da saúde e da motivação para o trabalho e têm dois eixos de sentido: o cuidado ao corpo físico e o cuidado ao corpo social.

\section{O cuidado ao corpo físico}

Os dados empíricos evidenciaram que o cuidado realizado pelos profissionais de enfermagem tem por referência o corpo, em sua forma e em seu conteúdo - o corpo obeso. Nesta categoria, eles relacionam o significado do cuidado ao corpo, um corpo que tem um peso diferente de outros e que vai requerer certa quantidade de trabalho da enfermagem. Este significado valoriza a dimensão física e biológica, pois são estas dimensões que se apresentam concretamente e para as quais é requerida dos profissionais de enfermagem uma atuação direta e imediata.

O corpo físico é considerado objeto de trabalho e foco do cuidado do profissional de enfermagem:

Um diferencial a mais é o peso, o peso. Por exemplo, é diferente (Sujeito 2).

A diferença é a obesidade, pois você antes nunca cuidou de pacientes tão obesos, excessivamente obesos, quanto os outros pacientes que vêm para outro tipo de cirurgia! (Sujeito 3).

Quando ele chega, a gente já prepara o espírito pra saber se aquele paciente vai dar trabalho de acordo com a obesidade dele. Aquele paciente de 130 quilos tem bem menos dificuldade do que aquele de 160, 180, por causa das condições(Sujeito 1).

O corpo do cuidado é um corpo "diferente", tem muito mais peso, e a pessoa se distingue de outros pacientes pelo fato de ser obesa. Para o profissional de enfermagem, o corpo do cuidado é um corpo que relaciona diretamente o trabalho com o sobrepeso: pessoas que têm no peso três dígitos, como 130, 160, 180, demandam mais trabalho para o profissional que pessoas com o menor peso.

Considerando que os significados são social e culturalmente construídos, para os profissionais de enfermagem, o corpo se constitui em um objeto simbólico, valorado pelo tamanho e pelo peso em sua relação com um maior trabalho para cuidar. Em decorrência disto, ele se mobiliza, ele "prepara o espírito" para cuidar deste corpo, marcado pela sua forma, tamanho e peso. Sobre isto é importante destacar o uso dos termos gordo e obeso. O corpo gordo se insere no discurso do senso comum, não tem critérios mensuráveis, e oscila entre a valorização e o preconceito na história, já o corpo obeso é do âmbito médico. Atualmente a palavra "gordo" tem significado ofensivo, sendo discriminatório, e o termo "obeso" é considerado politicamente correto, pois, sendo do âmbito biomédico, foi se medicalizando a partir do século XVIII(17).

No contexto da enfermagem, o cuidado a este corpo envolve contato, força, conhecimento e sua mobilização principalmente para aqueles que cuidam nas instituições hospitalares em especial, nas situações cotidianas em clínica cirúrgica, pois o cuidado implica mobilizá-lo, sendo que nas situações pós-cirúrgicas imediatas, esta mobilização requererá maior força física, pois a dependência do doente é total. A organização do trabalho de enfermagem nas unidades de internação é delegada de modo que cada profissional realiza sua atividade sozinha, realizada por um único profissional, porém, quando há um doente "obeso mórbido", é preciso mobilizar ajuda de outros para realizar o cuidado.

O cuidado orientado requer a incorporação de recursos humanos e tecnologias, equipe de profissionais, equipamentos, instrumentos e técnicas de trabalho singulares. Assim, na medida em que para cuidar estão relacionados os limites da instituição, para a prática concreta do profissional, o cuidado deve ser analisado com base na categoria do trabalho(3).

Nos relatos dos profissionais de enfermagem, os limites nos recursos relacionam o cuidado à pessoa obesa, ao peso e à forma do corpo:

Às vezes você não tem um leito adequado que suporte o peso dele, uma maca adequada que suporte o peso dele, tudo que você tem que fornecer são o conforto e o bem- 
estar para esse paciente que tem que ficar internado, poucos dias que ele fica aqui, é esse lado mais de equipamento [palavra dita pausadamente] ali você encontra dificuldades não nos cuidados em si do paciente, só isso (Sujeito 3).

Muitas das vezes não há estrutura, a cama não levanta, a cama não abaixa (Sujeito 2).

Primeiro que conta muito são as condições de trabalho, nós temos deficiência de material, de cama. Nós temos deficiência de materiais! (Sujeito 1).

Há ênfase sobre a deficiência dos recursos físicos. $\mathrm{O}$ cuidado de enfermagem ao corpo que é obeso requer estrutura, equipamentos e mobiliários que suportem a forma e o peso da pessoa. Em situações rotineiras, por vezes, a precariedade da estrutura física e de materiais pode passar despercebida aos profissionais de enfermagem, mas não quando se trata do cuidado à pessoa obesa, já que nesta situação estão envolvidos riscos à segurança dela e a dos profissionais. Daí o significado deste aspecto nos relatos dos profissionais de enfermagem.

Os fatores culturais de corpo desempenham papel importante na saúde, inclusive no hospital, cujo espaço, embora considerado formal para a prestação de cuidados em saúde, intrinsecamente está relacionado ao modelo biomédico(18), não sendo acolhedor para o doente, como expressam os profissionais. Este espaço contribui para a significação, em nossa cultura, de exclusão da pessoa obesa.

Ter espaço, equipamentos, instrumentos e recursos humanos adequados valoriza o cuidado prestado pelos profissionais de enfermagem. O cuidado de enfermagem tem por referência o espaço, ou seja, o local onde os profissionais cuidam, antes e após o procedimento cirúrgico; também valoriza os meios necessários para cuidar - a maca, o equipamento, a estrutura, um leito com recursos de mobilização do indivíduo e os materiais adequados necessários. A desregulamentação das condições de trabalho podem gerar sofrimento ao trabalhador de enfermagem ${ }^{(18)}$.

O leito também é valorizado, pois o cuidado de enfermagem é realizado neste local e por meio dele. Ele é indispensável, já que deve proporcionar as condições para a realização do cuidado, adequando-se à forma e ao peso do corpo da pessoa, ao mesmo tempo em que possibilita ao doente sua mobilidade e sua movimentação. Os recursos materiais estão diretamente ligados às dificuldades que os profissionais de enfermagem enfrentam, pois fornecem conforto e segurança para quem cuida e para quem é cuidado(5). Ainda sobre o espaço do cuidado, os profissionais valorizam o ambiente físico, em especial o banheiro, fundamental para o cuidado de higiene e para as eliminações fisiológicas:

Ambiente físico do hospital não oferece condições para esse paciente (Sujeito 1).

Não tem banheiro [ênfase], disponível pra aquela situação na maioria das vezes são 150, 180 quilos (Sujeito 2).

O descumprimento desta regulamentação pelas instituições de saúde tem sido atribuído a seu custo elevado(5) e vem influenciando o modo como o cuidado de enfermagem é realizado por estes profissionais. As adequações do espaço do cuidado nas instituições possibilitam ambiente de acolhimento e humanização bem como condições para o profissional de enfermagem desenvolver suas ações com qualidade, e, embora existam regulamentações que orientem tal adequação, elas nem sempre tem sido seguidas.

Os significados do corpo da pessoa obesa para os profissionais de enfermagem também relacionam a necessidade de apoio da equipe. O trabalho de enfermagem como um trabalho coletivo se constitui como um aspecto relevante para o cuidado, implicando responsabilidade de um profissional com o outro de sua equipe:

A gente se une igual formiguinha pra ajudar. Agora, o que eu falei pra você, equipe é equipe de trabalho, né? Você tem uma equipe, todo mundo se ajuda. Não que ninguém fique especificamente sozinho, fazendo força (Sujeito 1).

Ajuda por exemplo, de... Acompanhante, como de coleguismo (Sujeito 2).

Todos falam, todos da área da saúde sempre têm que ir reforçando, aquela equipe multidisciplinar é a enfermagem, a medicina, a psicologia, todos, isso faz com que o paciente saia melhor daqui (Sujeito 3).

Para o cuidado, é preciso que o profissional de enfermagem tenha o apoio de outro, pois o cuidado tem 
por base um corpo grande e pesado. Os relatos dos profissionais destacam a importância de sentimentos como companheirismo, solidariedade entre os membros da equipe de enfermagem como entre outros profissionais de saúde.

Os recursos humanos foram destacados, pois as demandas para o cuidado levam em consideração o corpo físico do doente, requerendo integração entre profissionais da área e de outras áreas. Os diversos olhares privilegiam quem é cuidado, ao desafiar a equipe a trabalhar de modo a favorecer a integração interdisciplinar ${ }^{(5,19)}$.

Nos relatos dos profissionais de enfermagem, foi possível visualizar que o cuidado à pessoa obesa tem o corpo como sua centralidade, porém, ao descreverem as dificuldades e os limites do cuidado quanto às estruturas físicas, aos recursos humanos e aos equipamentos, revelam que as condições de trabalho são precárias, desfavorecendo e desqualificando o trabalho de enfermagem neste âmbito. Desta forma, as práticas discursivas e não discursivas atravessam a construção do sujeito obeso(17). E o cuidado de enfermagem centrado na pessoa obesa ainda está em construção, pois é preciso desconstruir um cuidado que ainda exclui para um modelo de cuidado inclusivo.

\section{O cuidado ao corpo social}

Os profissionais de enfermagem revelam como é significativo o corpo físico da pessoa em condição de obesidade, requerendo meios adequados para cuidar delas, porém revelam também que os significados atribuídos ao cuidado a elas integram dimensões sociais e culturais. As pessoas por elas cuidadas e que se submetem à cirurgia de redução de peso estão inseridas em um contexto social e cultural reconhecido pelos profissionais de enfermagem. Nesse estudo, há a consideração da história da pessoa:

Você se preocupa primeiramente assim, a história do paciente, se teve acompanhamento[...] Porque às vezes $o$ paciente vem pra cá e apresenta uma certa ansiedade em relação a esse tipo de cirurgia, e você percebe assim... Aquele nervosismo, aquela ansiedade, ele não está bem pronto, bem preparado e isso vai se refletir no pósoperatório, que é muito nítido, depois... (Sujeito 3).
Por mais que ele já venha preparado, ele vem... Ele se sente retraido, ele se sente com medo, ele sente vergonha... É um paciente... com o qual... A gente tem que ter um pouco mais de cuidado ao lidar com ele pra que até então ele não desista (Sujeito 2).

O profissional de enfermagem reconhece a importância do período pré-operatório, pois é nesta fase e na interação profissional-paciente que é possível apreender como está o estado emocional para a realização da cirurgia, em especial, a cirurgia de redução de peso.

A cirurgia de redução de peso tem implicações psicoemocionais, pois envolve o reconhecimento das condições sociais, mas também pessoais e de mudança comportamental. Neste contexto, os profissionais deste estudo dão significado a um procedimento cirúrgico, que associa ao modelo biomédico, questões relativas à história do paciente, sentimentos como medo, retraimento, vergonha, respectivamente, de âmbito biográfico, emocional, social e cultural. Neste sentido, há a necessidade de avançar nesta questão e reconhecer que as atividades relacionadas à saúde não se limitam apenas ao modelo biomédico, pois outras dimensões socioculturais se integram à condição de adoecimento ${ }^{(20)}$, demandando ampliar o cuidado para além do corpo físico.

O tratamento cirúrgico às pessoas com obesidade segue rigorosos critérios técnicos, porém há um forte componente social e cultural relacionado à cultura do corpo, descrito pelos profissionais de enfermagem, que requerem outros saberes e tecnologias para cuidar destas pessoas. Esta visão ampliada do cuidar de enfermagem pode ser apreendida quando se insere a interpretação como um componente importante para compreender o doente e como isto traz significados ao profissional que dele cuida.

O cuidado de enfermagem com vistas à integralidade pode ser possível ao se considerar a interpretação das pessoas envolvidas no processo do cuidado, do profissional de enfermagem e das pessoas com obesidade, buscando integrar aos aspectos biomédicos, os fatores socioculturais e emocionais. Os profissionais de enfermagem, ao reconhecerem em suas narrativas que as pessoas das quais cuidam vivenciam sentimentos de desvalorização relacionados ao padrão social do corpo, e que moralmente as afetam, como relatam "Ele se sente 
retraído, ele se sente com medo, ele sente vergonha", integram ao cuidado de enfermagem dimensões sociais e culturais, evidenciando que o atendimento a estas dimensões qualifica positivamente o cuidado ofertado.

Outro aspecto que caracteriza um cuidado ao corpo social é a valorização, pelo profissional de enfermagem, da real motivação que levou a pessoa obesa a se submeter à cirurgia:

É que nós temos vários tipos de pacientes bariátricos, nós temos aquele que quer mesmo voltar a ter saúde, quer ficar bem, e nós temos aquele que está preocupado só com a estética, que a família está cobrando, que o marido está deixando (Sujeito 1).

O relato do profissional destaca os tipos de pessoas obesas segundo as motivações para a cirurgia bariátrica: aquele que vem por cobrança social, o que vem em busca de saúde e o que busca pelo corpo reduzir a rejeição. Na descrição dos motivos, os profissionais passam a reconhecer que ao procedimento cirúrgico há os valores sociais de corpo. Embora haja um contexto histórico, social, cultural e político em torno da construção do corpo, em nossa sociedade atual ainda é muito presente a responsabilização da pessoa sobre o seu corpo.

O culto ao corpo responsabiliza cada pessoa por sua aparência, possibilitando que a "forma" do corpo possa conceder atributos morais: se a pessoa for obesa, ela poderá ser relacionada à preguiça, falta de vontade, descuido etc.; e questões como falhas nos serviços públicos de saúde, más condições financeiras, desinformação sobre alimentos saudáveis nem sempre são levados em consideração. A cirurgia tem sido vista como um recurso que a própria pessoa obesa tem buscado para cuidar do seu corpo(17). A responsabilização individual é reiterada.

O corpo social também pode ser destacado quando a profissional de enfermagem descreve que as pessoas submetidas à cirurgia para redução de peso podem se decepcionar com o resultado:

Eu já vi pessoa que se esconde dentro da sua casa, porque ela passa a se sentir tão feia, tão feia, fragilizada, é assim que começa [...]. Mas tem aqueles [...] Faladeira assim, cheio de planos, cheio... sabe... de sonhos. A gente dá aquele incentivo! [sorriso]. Assim... é um novo rumo, uma nova história, o bariátrico entra aqui, quando ele sai, é uma nova história que está começando (Sujeito 1).

As profissionais de enfermagem entendem que ao lado da possibilidade de uma "nova história que tá começando" pela cirurgia, podem ocorrer alterações psicoemocionais que alteram profundamente a vida das pessoas obesas. As consequências da cirurgia bariátrica podem afetar a pessoa em sua autoestima, no autoconceito, causar rupturas nas histórias de vida delas, pela forma como o corpo, seus hábitos e o emocional foram afetados, evidenciando que o profissional se preocupa com os aspectos socioculturais.

O cuidado do profissional de enfermagem vai além do modelo biomédico na medida em que ele revela nos seus modos como ele valoriza os vínculos entre profissional e pessoa obesa. O estabelecimento de vínculos com o paciente é fundamental e visa a diminuir a ansiedade ${ }^{(21)}$. Ao descrever a escuta, o acolhimento, o diálogo, busca-se a compreensão da interpretação do outro.

O cuidado do profissional ao corpo social também está presente nas formas como o profissional de enfermagem lida com a pessoa obesa:

Primeiro a gente vai sentar perto pra ver como é que está... O humor dele... Como é que está a cabeça dele [...]. De vez em quando você passa já dá um bom-dia alegre, para ver como é que está.Depois você cuida. Aí você vem. Você senta primeiro com ela. Conversa com ela. Vê a limitação dela. Vê se ela está com medo [...]. Você passa segurança pra ela, que não vai abrir, e explica, ensina a virar (Sujeito 1).

Você vê, atenta mais pra essa ansiedade do paciente. Em si. E o preparo psicológico pré-operatório. Que ela vai para o centro cirúrgico, que lá tem uma equipe que vai recebê-la. Que a ansiedade é como vai ser lá no centro cirúrgico. Que vai receber ela muito bem, que é anestesista, da enfermagem, e que ela não precisa ter medo, que se ela veio para isso, que é importante... Se é importante para ela, é a hora dela fazer. Então tem que tentar tranquilizar a paciente (Sujeito 3).

A aproximação do profissional da pessoa em obesidade é cuidadosa e processual, utiliza os sentidos da visão, da comunicação, do tempo e das palavras positivas. O profissional tem o cuidado de assumir uma postura de igualdade com a pessoa obesa e fala, ensina, informa, 
buscando captar suas necessidades. Demonstra ainda atitudes que revelam a preocupação com as reações da pessoa durante a internação e com o procedimento. Enfatiza que é importante a inclusão de fatores relacionais no seu cuidado com ela.

A perspectiva hermenêutica no cuidado compreende que ele não é fruto de um saber centrado no conhecimento científico-tecnológico, mas valoriza o diálogo, buscando cindir os horizontes dos sujeitos no processo, buscando a produção de compartilhamentos, a familiarização e a apropriação mútuos; reconhecendo dessa forma o caráter existencial, intersubjetivo e dialógico da experiência das pessoas que compartilham espaços em saúde e que se orientam para a construção de cada um no processo(22).

Pode-se pensar se este modo de cuidar é decorrente dos processos individuais vivenciados pelo profissional, sua história de vida, ou se trata de uma cultura coletiva que deixa marcas nos membros do grupo ou da sociedade ${ }^{(23)}$.

O cuidado da enfermagem vai além do corpo físico, quando por meio da comunicação intenciona o cuidado verbal, visando a transmitir calma e tranquilidade com o objetivo de deixar o paciente a vontade durante a realização de procedimentos técnicos.

O cuidado de enfermagem com vistas ao corpo social na pessoa obesa é considerado "complicado", em especial se for uma pessoa adulta madura e requerer cuidados de higiene:

Talvez uma palavrinha assim, ele já tira. Porque é um paciente complicado... já basta ele chegar aqui, por exemplo, com 60 anos com 180 quilos. Não é fácil, nunca ninguém deu banho, nunca ninguém mexeu nele. (Sujeito 2).

Os termos presentes nas narrativas dos profissionais como "tirar", indicando uma reação grosseira do doente, e "complicado", que relaciona que a cirurgia tem também implicações sociais, culturais, comportamentais e psicoemocionais para o doente, revelam que o cuidado a estas pessoas é complexo, pois de um lado há o tratamento do corpo, mas, por outro, esta cirurgia ocorre em pessoas marcadas social e culturalmente pela obesidade e que irão requerer cuidados profissionais por longo período.
A limitação corporal e a de mobilidade são aspectos narrados pelos profissionais, que os afetam emocionalmente, pois comprometem a autonomia e a independência do doente, principalmente para a realização das atividades básicas de higiene e eliminação. Cuidar delas também envolve desafiar os valores socialmente instituídos, em especial, quando é preciso cuidar de espaços defendidos como "íntimos" e "privados", o corpo do outro, que tem também uma dimensão ética e moral.

O cuidado do profissional ao corpo social tem por base as percepções e sensações da pessoa em sua trajetória, desde a sua internação, para a efetivação do procedimento cirúrgico, até o seu retorno ao leito na clínica, como relata:

o primeiro passo que faz é uma conversa... Orientando...[...]. Então você tem que ter aquele carinho especial de conversar, de ter paciência com ele, começa com uma história, primeiro vai pra UTI, ele já fica assustado, porque vai pra UTI [...] tudo isso a gente tem que chegar, receber esse paciente e passar para ele: "é um protocolo, você vai lá ... porque você não vai passar mal, mas é porque faz parte da cirurgia". Então isso, a gente tem assim bem a sensibilidade para conversar (Sujeito 1).

Você precisa ter certo cuidado como conversar, como você vai cuidar, como você vai tratar desse paciente, tudo é muito o lado psicológico, não é tanto a cirurgia em si. (Sujeito 3).

Por meio da comunicação, o profissional de enfermagem busca apreender e relativizar o ritual da trajetória de cuidado ao doente com obesidade ouvindo, sentindo, conversando e tendo paciência, revelando a preocupação, visto que a hospitalização, a cirurgia, a Unidade de Terapia Intensiva (UTI) podem marcar a vida dessas pessoas.

$\mathrm{Na}$ interação entre o profissional e a pessoa com obesidade, o cuidado ao corpo social ocorre quando este profissional é sensível aos comportamentos, gestos, falas e às necessidades de saúde do outro.

A empatia é uma atitude que possibilita compreender as necessidades de saúde da pessoa que se submete à cirurgia:

Não é para todos, não é todos que têm a mesma sorte [...], eu tenho parentes meus que fizeram essa cirurgia, e estão... 
Normais... Mas em vista do que eu vejo muito no hospital, são mais infelizes do que felizes [...]. Deve ser terrível, você imagina você ficar sem comer tudo o que você gosta. Que a vida inteira você comeu. Deve ser terrível (Sujeito 2).

No contexto do cuidado, as experiências pessoais se agregam às experiências profissionais, influenciando na forma como deve prestar o cuidado. Os profissionais revelam que o cuidado às pessoas obesas não se limita ao cuidado técnico-científico, eles valorizam suas vidas por meio dos diferentes modos de cuidar delas e reconhecem que a cirurgia repercute profundamente na vida dessas pessoas. A cirurgia é um marco para as mudanças na vida, uma vez que, ao mudar seu corpo, poderão alcançar os valores socialmente compartilhados de corpo normal, de saúde, de família, de responsabilidade, de esforço, entre outros. Contudo, também podem ser afetados moralmente, em especial quando se distanciam desses valores.

As negatividades do procedimento reveladas como "mais infelizes do que felizes" associam a mudança radical no hábito de vida, cujos estilos e valores deverão ser reconstruídos. São mudanças nos valores pessoais que se agregam aos valores socialmente compartilhados, em especial, ao valor de comer o que se gosta e privar-se daquilo que se relaciona à felicidade: a comida.

Os significados do corpo são construídos segundo os contextos socioculturais que compartilham: assim, para as classes populares, o corpo tem valor instrumental; para as classes médias, tem valor reflexivo; para as classes populares, é imoral olhar para o corpo; para a classe média, é imoral não cuidar do próprio corpo, pois nesta classe o corpo deve ser bem cuidado e belo(8). Para os profissionais de enfermagem deste estudo, o corpo do cuidado é um corpo obeso, que requer recursos humanos, materiais e equipamentos para cuidar, e as pessoas com este corpo vivenciam situações biográficas, sociais e culturais e psicoemocionais.

A noção de pessoa não separa o corpo da pessoa, mas o entende como sujeitos em cultura, que pensam e vivem o corpo, a saúde e a doença, e, embora no discurso biomédico o corpo e suas funções sejam compreendidos como um fenômeno neurofisiológico, a perspectiva sociocultural compreende que o corpo não existe fora do sistema de símbolos, mas se constitui em um espaço simbólico, cujos significados são atribuídos pela coletividade ${ }^{(21)}$.

Na cultura contemporânea, o ser do cuidado em saúde é investido de valores, sentidos e significados, por isso, com múltiplas possibilidades de se construir, articulando as práticas de saúde, os sentidos e os valores, sendo a prática em saúde o espaço em que é possível apreender os símbolos que possibilitam compreender os significados e os sentidos. Sabe-se que atualmente dois paradigmas orientam as práticas da ação concreta: um que confere valor à ciência e à biomedicina e outro que valoriza o vigor, a força e a beleza e opera com as concepções de integralidade, desenvolvidas por profissionais mais "humanizados"(8).

\section{CONSIDERAÇÕES FINAIS}

Os profissionais de enfermagem concebem o cuidado às pessoas que se submetem à cirurgia para redução de peso como cuidado ao corpo físico e cuidado ao corpo social. Em relação ao corpo físico, revelam que é um corpo diferenciado, que necessita de estruturas, espaço, recursos materiais e humanos adequados para o cuidado. Já em relação ao corpo social, destacam que são pessoas que têm histórias de vida, requerem o uso de tecnologias relacionais com ênfase na observação, na escuta, na fala, no diálogo e no vínculo. Os profissionais consideram as pessoas que buscam a cirurgia para redução de peso fortemente influenciadas pelos aspectos sociais e culturais, por isso, requerem cuidados para além do cuidado biológico, um cuidado sensível.

Os resultados deste estudo possibilitam visualizar que nas atividades concretas relatadas pelos profissionais de enfermagem de saúde o modelo biomédico se mescla à valorização dos aspectos sociais, culturais e psicoemocionais, revelando uma direção para as práticas sensíveis ao reconhecer os significados e sentidos presentes nas narrativas dos profissionais.

O cuidado que os profissionais realizam está orientado a práticas integrais, já que buscam cuidar da pessoa obesa no âmbito do corpo físico e do corpo social. No contexto de suas práticas, relataram os limites da instituição, revelando que suas preocupações com a pessoa adoecida são coerentes com a forma como a obesidade ainda é vista em nossa sociedade e nas instituições de saúde. 
As práticas em saúde, ao se revelarem nos significados e nos sentidos expressos nas ações dos profissionais de enfermagem, mostram que elas estão em permanente construção social. Neste sentido, evidenciam que o ser humano tem uma grande capacidade e necessidade de atribuir sentido às coisas a partir de suas vivências com vistas a transformá-las. Daí a riqueza da compreensão dos significados da ação realizada pelos profissionais de enfermagem, possibilitada por estudos desta natureza.

\section{REFERÊNCIAS}

1. Ministério da Saúde. Obesidade. Cadernos de Atenção Básica - no 12 [Internet]. Brasília: Ministério da Saúde; 2006 [acesso em: 20 dez 2013]. Disponível em:

http://189.28.128.100/dab/docs/publicacoes/cadernos ab/abca d12.pdf.

2. Associação Brasileira para o Estudo da Obesidade e da Síndrome Metabólica. Diretrizes brasileiras de obesidade 2009/2010 [Internet]. $3^{\text {a }}$ ed. Itapevi: AC Farmacêutica; 2009 [acesso em: 20 dez 2013]. Disponivel em:

http://www.abeso.org.br/pdf/diretrizes brasileiras obesidade 20092010 1.pdf.

3. Pires D. A enfermagem enquanto disciplina, profissão e trabalho. Rev Bras Enferm [Internet]. 2009 [acesso em: $20 \mathrm{dez}$ 2013];62(5):739-44. Disponível em:

http://dx.doi.org/10.1590/S0034-71672009000500015.

4. Costa ACC, Ivo ML, Cantero WB, Tognini JRF. Obesidade em pacientes candidatos a cirurgia bariátrica. Acta paul. enferm. [Internet]. 2009 [acesso em: 20 dez 2013];22(1):55-9. Disponível em: http://dx.doi.org/10.1590/S0103-21002009000100009.

5. Tanaka DS, Peniche ACG. Assistência ao paciente obeso mórbido submetido à cirurgia bariátrica: dificuldades do enfermeiro. Acta paul. enferm. [Internet]. 2009 [acesso em: 20 dez 2013];22(5):618-23. Disponível em:

http://dx.doi.org/10.1590/S0103-21002009000500004.

6. Silva KL, Sena RR. Integralidade do cuidado na saúde: indicações a partir da formação do enfermeiro. Rev Esc Enferm USP [Internet]. 2008 [acesso em: $20 \mathrm{dez} 2013$ ];42(1):48-56.

Disponivel em: http://dx.doi.org/10.1590/S0080-

62342008000100007.

7. Ayres JRCM. O cuidado, os modos de ser (do) humano e as práticas de saúde. Saude soc. [Internet]. 2004 [acesso em: 20 dez 2013];13(3):16-29. Disponível em:

http://dx.doi.org/10.1590/S0104-12902004000300003.

8. Carvalho MCVS, Luz MT. Práticas de saúde, sentidos e significados construídos: instrumentos teóricos para sua interpretação. Interface (Botucatu) [Internet]. 2009 [acesso em: 20 dez 2013];13(29):313-26. Disponível em:

http://dx.doi.org/10.1590/S1414-32832009000200006.

9. Uchôa E, Vidal JM. Antropologia médica: elementos conceituais e metodológicos para uma abordagem da saúde e da doença. Cad Saude Publica [Internet]. 1994 [acesso em: 20 dez 2013];10(4):497-504. Disponivel em:

http://dx.doi.org/10.1590/S0102-311X1994000400010.

10. Boehs AE, Monticelli M, Wosny AM, Heidemann IBS, Grisotti $M$. A interface necessária entre enfermagem, educação em saúde e o conceito de cultura. Texto Contexto Enferm [Internet]. 2007 [acesso em: $20 \mathrm{dez} 2013] ; 16(2): 307-14$.
Acreditamos que os resultados deste estudo contribuíram para a compreensão do cuidado de enfermagem como um cuidado que se relaciona à própria dimensão sociocultural do ser que cuida, o profissional de enfermagem. Também evidenciam que a perspectiva socioantropológica integrada às pesquisas sobre o cuidado de enfermagem para as pessoas que se submetem à cirurgia para redução de peso possibilita a valorização dos comportamentos, das crenças e dos significados como elementos importantes para a qualificação do cuidado.

Disponível em: http://dx.doi.org/10.1590/S010407072007000200014.

11. Ide P, Farber ES, Lautz D. Perioperative Nursing Care of the Bariatric Surgical Patient. AORN J [Internet]. 2008 [acesso em: 20 dez 2013];88(1):30-58. Disponível em: http://dx.doi.org/10.1016/j.aorn.2008.02.015.

12. Mulligan AT, McNamara AM, Boulton HW, Trainor LS, Raiano C, Mullen A. Best practice updates for nursing care in weight loss surgery. Obesity (Silver Spring) [Internet]. 2009 [acesso em: 20 dez 2013];17(5):895-900. Disponível em:

http://dx.doi.org/10.1038/oby.2008.579.

13. Marzen-Groller KD, Cheever KH. Facilitating Students' Competence in Caring for the Bariatric Surgical Patient: The Case Study Approach. Bariatr Nurs Surg Patient Care [Internet]. 2010 [acesso em: $20 \mathrm{dez} 2013$ ];5(2):117-25. Disponível em: http://dx.doi.org/10.1089/bar.2010.9924.

14. Reedy S, Blum K. Applying middle-range nursing theory to bariatric surgery patients: experiencing transitions. Bariatr Nurs Surg Patient Care [Internet]. 2010 [acesso em: $20 \mathrm{dez}$

2013];5(1):35-43. Disponível em:

http://dx.doi.org/10.1089/bar.2009.9940.

15. Marcelino LF, Patrício ZM. A complexidade da obesidade e o processo de viver após a cirurgia bariátrica: uma questão de saúde coletiva. Cien Saude Colet [Internet]. 2011 [acesso em: 20 dez 2013];16(12):4767-76. Disponível em:

http://www.scielo.br/scielo.php?script=sci arttext\&pid=S1413$81232011001300025 \& \operatorname{lng}=e n \& n r m=i s o \&$ tlng=pt.

16. Minayo MCS. O desafio do conhecimento: pesquisa

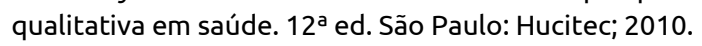

17. Gonçalves SD, Miranda LL. Biopolítica e confissão: cenas do grupo terapêutico com pacientes obesos. Psicol. Soc. [Internet]. 2012 [acesso em: 20 dez 2013];24(esp.):94-103. Disponível em: http://dx.doi.org/10.1590/S0102-71822012000400014.

18. Medeiros SM, Ribeiro LM, Fernandes SMBA, Veras VSD. Condições de trabalho e enfermagem: a transversalidade do sofrimento no cotidiano. Rev. Eletr. Enf. [Internet]. 2006 [acesso em: 20 dez 2013];8(2):233-40. Disponível em:

http://www.fen.ufg.br/revista/revista8_2/v8n2a08.htm.

19. Raynaut C. Interdisciplinaridade e promoção da saúde: o papel da antropologia. Algumas idéias simples a partir de experiências africanas e brasileiras. Rev Bras Epidemiol [Internet]. 2011 [acesso em: 20 dez 2013];5 Supl. 1:43-55. Disponível em: http://dx.doi.org/10.1590/S1415790X2002000400006.

20. Oliveira FA. Antropologia nos serviços de saúde: integralidade, cultura e comunicação. Interface (Botucatu) [Internet]. 2002 [acesso em: $20 \mathrm{dez}$ 2013];6(10):63-74. Disponível em: http://dx.doi.org/10.1590/S1414$\underline{32832002000100006}$. 
21. Alves CA, Deslandes SF, Mitre RMA. Desafios da humanização no contexto do cuidado da enfermagem pediátrica de média e alta complexidade. Interface (Botucatu) [Internet]. 2009 [acesso em: 20 dez 2013];13 Supl. 1:581-94. Disponível em: http://dx.doi.org/10.1590/S1414-32832009000500010.

22. Ayres JRCM. Uma concepção hermenêutica de saúde. Physis [Internet]. 2007 [acesso em: $20 \mathrm{dez} 2013] ; 17(1): 43-62$.

Disponivel em: http://dx.doi.org/10.1590/S0103-

73312007000100004 .

23. Sarti C. Corpo e Doença no trânsito de saberes. Rev. bras. Ci. Soc. [Internet]. 2010 [acesso em: 20 dez 2013];25(74):77-90.

Disponivel em: http://dx.doi.org/10.1590/S0102$\underline{69092010000300005}$.

Artigo recebido em 06/06/2012.

Aprovado para publicação em 12/08/2013.

Artigo publicado em 31/12/2013. 